\title{
Magnetic nanoparticle supported hyperbranched polyglycerol catalysts for synthesis of $\mathbf{4 H}$-benzo[b]pyran
}

\author{
Mohammad Ali Nasseri • Seyed Mohsen Sadeghzadeh
}

Received: 7 November 2012/ Accepted: 29 May 2013/Published online: 12 July 2013

(c) The Author(s) 2013. This article is published with open access at Springerlink.com

\begin{abstract}
A magnetic nanoparticle supported hyperbranched polyglycerol catalyst was prepared readily from inexpensive starting materials in aqueous medium that catalyzed the synthesis of $4 \mathrm{H}$-benzo[b]pyran under solventfree conditions at room temperature. X-ray diffraction, transmission electron microscopy, thermal gravimetric analysis, vibrating sample magnetometry, and selectedarea electron diffraction were employed to characterize the properties of the synthesized catalyst. Its high catalytic activity and ease of recovery from the reaction mixture using an external magnet, and the possibility of reusing several times without significant loss of performance are additional eco-friendly attributes of this catalytic system.
\end{abstract}

Keywords Magnetic nanoparticle - $4 H$-Benzo[b]pyran * Solvent-free · One-pot synthesis · Green chemistry

\section{Introduction}

In recent years, core-shell multi-components have attracted intense attention because of their potential applications in catalysis [1]. Unlike single-components that can supply only one function, core-shell multi-components can integrate multiple functions into one system for specific applications [2-6]. Moreover, the interactions between different components can greatly improve the performance

M. A. Nasseri $(\bowtie) \cdot$ S. M. Sadeghzadeh

Department of Chemistry, College of Sciences,

Birjand University, PO Box 97175-615, Birjand, Iran

e-mail: mohammadali.nasseri@yahoo.com of the multi-component system and even generate new synergetic properties. Among core-shell structured composites, those with a magnetic core and functional shell structures have received special attention because of their potential applications in catalysis, drug storage/release, selective separation, chromatography, and chemical or biologic sensors [7-12]. The magnetic core has good magnetic responsiveness, and can be easily magnetized. Therefore, composites with magnetic cores can be conveniently collected, separated, or fixed using an external magnet.

$4 H$-Benzopyran derivatives are a major class of heterocycles, and $4 H$-pyran derivatives have attracted strong interest due to their useful biological and pharmacological properties such as anticoagulant, spasmolytic, diutretic, anticancer [13], and antianaphylactin characteristics [14]. $4 H$-Pyrans also occur in various natural products [15] and some benzopyran derivatives have been reported to have photochemical activities [16]. Development of $4 H$-pyran synthesis has been of considerable interest in organic synthesis, because of their wide-ranging biological and pharmaceutical activities. Consequently, numerous methods for the synthesis of $4 H$-pyrans have been reported. A variety of reagents, such as $\mathrm{Yb}(\mathrm{PFO})_{3}$ [17], tetramethylammonium hydroxide [18], $\mathrm{Na}_{2} \mathrm{SeO}_{4}$ [19], $\mathrm{LiBr}$ [20], $\mathrm{NaBr}$ [21], MgO [22], SB-DABCO [24], and the use of microwave irradiation [23], were found to catalyze these reactions. However, some of the reported methods have the following drawbacks: use of expensive reagents, long reaction times, low product yields, and use of an additional microwave oven. Herein we report the fabrication of hyperbranched polyglycerol (HPG) incorporated into mesoporous magnetite nanoparticles (MNP) that catalyze the synthesis $4 H$-benzo[b]pyrans under solvent-free conditions at room temperature (Scheme 1). 


\section{Results and discussion}

We report the synthesis of a magnetic particle-based solid polymer with a high density of HPG groups and discuss its performance as a novel strong and stable solid polymer. We were intrigued by the possibility of applying anhydrous dioxane and nanotechnology to the design of a novel, active, recyclable, and magnetically recoverable HPG derivative for the first time (Fig. 1).

Normally, $\mathrm{N}_{2} \mathrm{H}_{4} \cdot \mathrm{H}_{2} \mathrm{O}$ can serve as either an oxidant or a reducer in alkaline solution. $\mathrm{Ni}^{2+}$ can be reduced easily to $\mathrm{Ni}$ in alkaline solution by $\mathrm{N}_{2} \mathrm{H}_{4} \cdot \mathrm{H}_{2} \mathrm{O}$. However, it is difficult to reduce $\mathrm{Fe}^{2+}$ to $\mathrm{Fe}$ directly by $\mathrm{N}_{2} \mathrm{H}_{4} \cdot \mathrm{H}_{2} \mathrm{O}$ because the electromotive force of the oxidation reaction of $\mathrm{Fe}^{2+}$ to $\mathrm{Fe}^{3+}(0.66 \mathrm{~V})$ is much larger than that of the reduction reaction from $\mathrm{Fe}^{2+}$ to $\mathrm{Fe}(0.283 \mathrm{~V})$. Thus, $\mathrm{Fe}^{2+}$ is more likely to be oxidized to $\mathrm{Fe}^{3+}$ when treated by $\mathrm{N}_{2} \mathrm{H}_{4} \cdot \mathrm{H}_{2} \mathrm{O}$ in alkali solution. In this experiment, however, when $\mathrm{Fe}^{2+}$ and $\mathrm{Ni}^{2+}$ coexist in the solution, $\mathrm{Fe}^{2+}$ ions can be reduced easily to $\mathrm{Fe}$ under the assistance of $\mathrm{Ni}^{2+}$ to form $\mathrm{FeNi}_{3}$ alloy. The reduction reaction can be expressed as follows:

$3 \mathrm{Ni}^{2+}+\mathrm{Fe}^{2+}+2 \mathrm{~N}_{2} \mathrm{H}_{4}+8 \mathrm{OH}^{-} \rightarrow \mathrm{FeNi}_{3}+2 \mathrm{~N}_{2}+8 \mathrm{H}_{2} \mathrm{O}$.

\section{$X$-ray power diffraction}

The structural properties of synthesized $\mathrm{FeNi}_{3} / \mathrm{SiO}_{2} / \mathrm{HPG}$ nanoparticle were analyzed by $\mathrm{X}$-ray power diffraction

\section{Scheme 1}

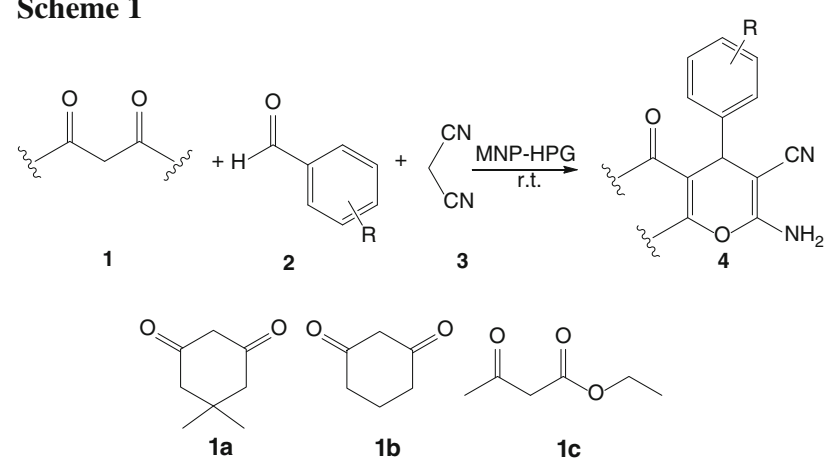

(XRD). As shown in Fig. 2, the XRD pattern of the synthesized $\mathrm{FeNi}_{3} / \mathrm{SiO}_{2} / \mathrm{HPG}$ nanoparticle displays several relatively strong reflection peaks in the $2 \theta$ region of $40^{\circ}$ $80^{\circ}$, which is quite similar to those of $\mathrm{FeNi}_{3}$ nanoparticles reported by other groups. Three characteristic peaks for $\mathrm{FeNi}_{3}\left(2 \theta=44.3^{\circ}, 51.5^{\circ}, 75.9^{\circ}\right)$ from $(111),(200)$, and (220) planes were obtained. In addition, no iron and nickel oxides or other impurity phases were detected in the XRD patterns. The sharp and strong diffraction peaks confirm the good crystallization of the products. The broad band at $2 \theta=15.0^{\circ}-30.0^{\circ}$ can be assigned to the amorphous $\mathrm{SiO}_{2}$ shell (JCPDS No. 29-0085).

\section{High-resolution transmission electron microscopy}

High-resolution transmission electron microscopy (HRTEM) images of $\mathrm{FeNi}_{3}, \mathrm{FeNi}_{3} / \mathrm{SiO}_{2}$, and $\mathrm{FeNi}_{3} / \mathrm{SiO}_{2} /$ HPG MNPs are shown in Fig. 3. The average size of $\mathrm{FeNi}_{3}$ MNPs is about $15 \mathrm{~nm}$, and the aggregation of the nanoparticles can be discerned clearly (Fig. 3a). After being coated with a silica layer, the typical core-shell structure of the $\mathrm{FeNi}_{3} / \mathrm{SiO}_{2}$ MNPs can be observed. The dispersity of $\mathrm{FeNi}_{3} / \mathrm{SiO}_{2}$ MNPs is also improved, and the average size increases to about $20 \mathrm{~nm}$ (Fig. 3b). The average size of $\mathrm{FeNi}_{3} / \mathrm{SiO}_{2} / \mathrm{HPG}$ MNPs is about $60 \mathrm{~nm}$ (Fig. 3c), but aggregation of $\mathrm{FeNi}_{3} / \mathrm{SiO}_{2} / \mathrm{HPG}$ is more evident than that of $\mathrm{FeNi}_{3} / \mathrm{SiO}_{2}$ MNPs.

\section{Selected-area electron diffraction}

The selected-area electron diffraction (SAED) pattern taken from the prepared $\mathrm{FeNi}_{3} / \mathrm{SiO}_{2} / \mathrm{HPG}$ MNPs consists of typical polycrystalline rings, suggesting a nanocrystalline structure (Fig. 4). The diffraction peaks from (111), (200), (220), and (311) planes of (FCC)- $\mathrm{FeNi}_{3}$ are in total agreement with those of XRD.

\section{Thermogravimetric analysis}

The thermal behavior of $\mathrm{FeNi}_{3} / \mathrm{SiO}_{2} / \mathrm{HPG}$ MNPs (Fig. 5) was evaluated to be $1.5 \%$ according to thermogravimetric analysis (TGA). The analysis showed two decreasing peaks. The first peak appears at temperature around
Fig. 1 Schematic illustration of the synthesis for magnetic nanoparticle supported hyperbranched polyglycerol (MNP-HPG)

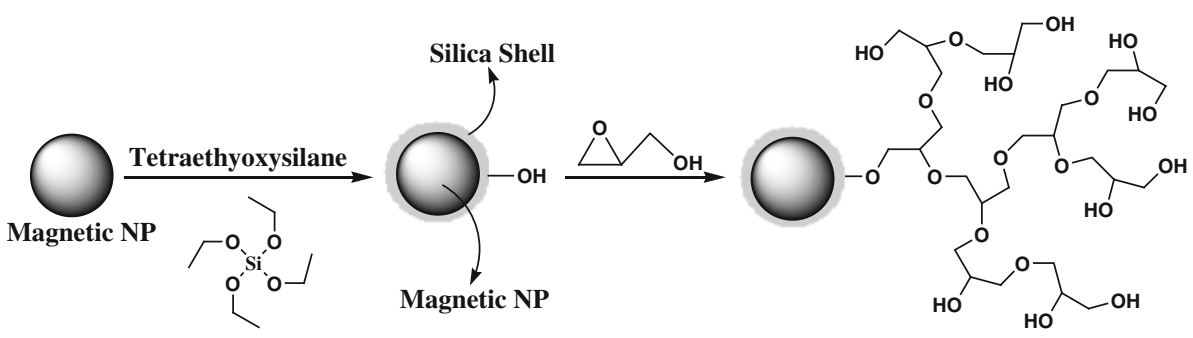


130-150 ${ }^{\circ} \mathrm{C}$ due to desorption of water molecules from the catalyst surface. This is followed by a second peak at $425-450{ }^{\circ} \mathrm{C}$, corresponding to the loss of the organic spacer group.

\section{Magnetic properties of $\mathrm{FeNi}_{3} / \mathrm{SiO}_{2} / \mathrm{HPG} \mathrm{MNP}$}

The magnetization curves of $\mathrm{FeNi}_{3}$ and $\mathrm{FeNi}_{3} / \mathrm{SiO}_{2} / \mathrm{HPG}$ MNPs were further recorded at room temperature (Fig. 6). The magnetizations were expressed in units of emu per gram of powder. The two measured samples display a superparamagnetic behavior, as evidenced by a zero coercivity and remanence on the magnetization loop. The saturation magnetization value of the $\mathrm{FeNi}_{3} / \mathrm{SiO}_{2} / \mathrm{HPG}$ MNP is $25 \mathrm{emu} / \mathrm{g}$, which is lower than that of uncoated magnetic particles (about $60 \mathrm{emu} / \mathrm{g}$ ).

\section{Catalytic activity of $\mathrm{FeNi}_{3} / \mathrm{SiO}_{2} / \mathrm{HPG} \mathrm{MNPS}$}

The effect of solvent on this reaction was examined and the results obtained are summarized in Table 1 . In $n$-hexane, $\mathrm{CHCl}_{3}$, and dioxane (Table 1, entries 12-14), only a trace of product was observed. On the contrary, moderate yields could be achieved in other solvents (Table 1, entries 1-10). More strikingly, we found that the reaction proceeded

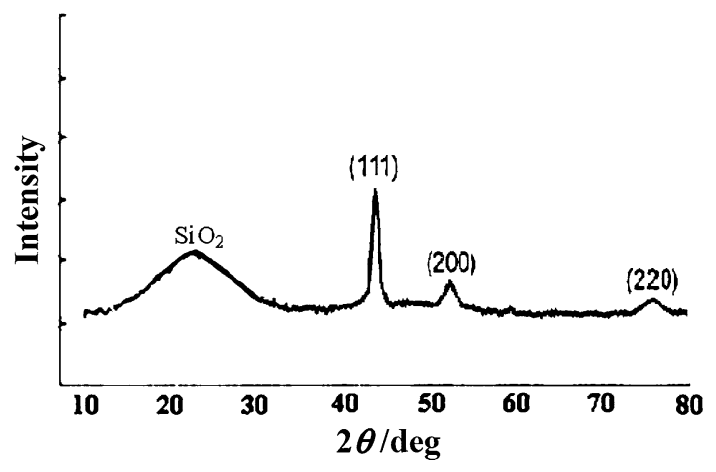

Fig. 2 X-ray power diffraction (XRD) analysis of MNP-HPG smoothly in solvent-free conditions and gave the desired product in $97 \%$ yield (Table 1, entry 11).

At this stage, the amount of catalyst necessary to promote the reaction efficiently was examined. It was observed that variation of the amount of $\mathrm{FeNi}_{3} / \mathrm{SiO}_{2} / \mathrm{HPG}$

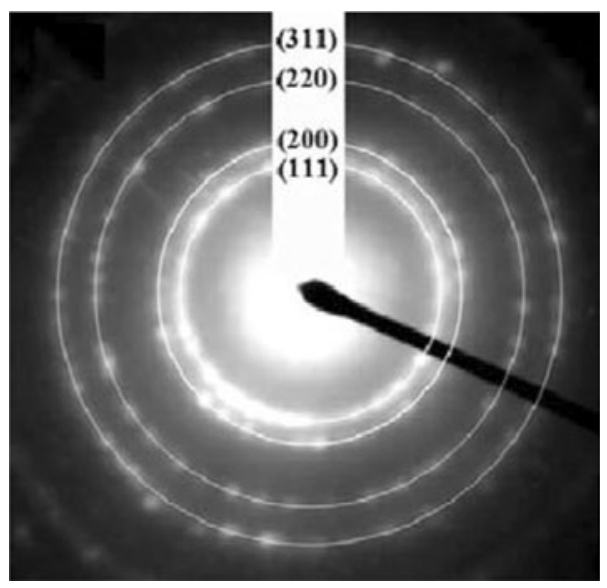

Fig. 4 Selected-area electron diffraction (SAED) pattern of $\mathrm{FeNi}_{3} /$ $\mathrm{SiO}_{2} / \mathrm{HPG}$ MNP

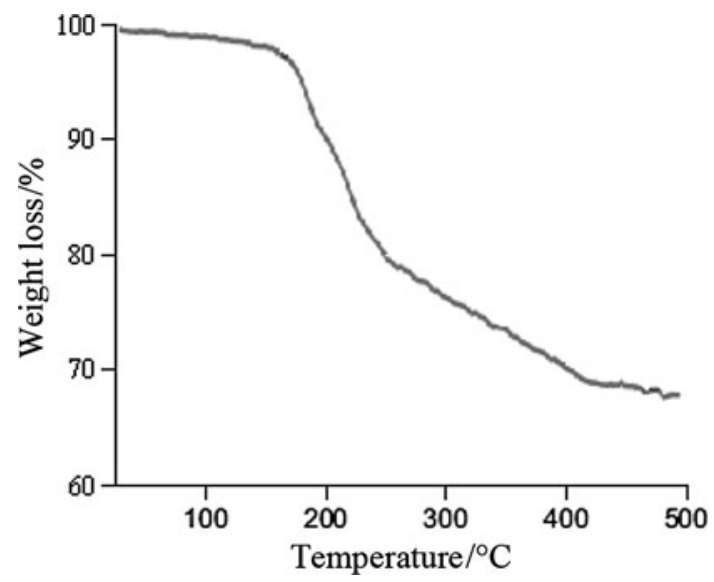

Fig. 5 Thermogravimetric analysis (TGA) of $\mathrm{FeNi}_{3} / \mathrm{SiO}_{2} / \mathrm{HPG} \mathrm{MNP}$
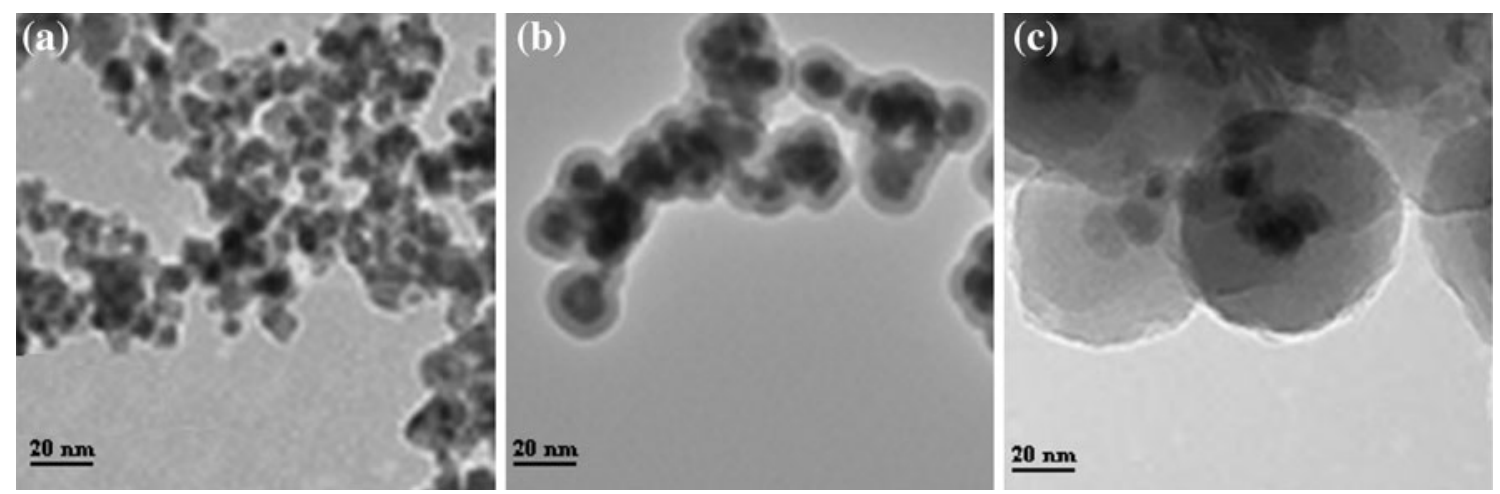

Fig. 3 High-resolution transmission electron microscopy (HRTEM) images of a $\mathrm{FeNi}_{3}, \mathbf{b} \mathrm{FeNi}_{3} / \mathrm{SiO}_{2}$, and $\mathbf{c} \mathrm{FeNi}_{3} / \mathrm{SiO}_{2} / \mathrm{HPG}$ 


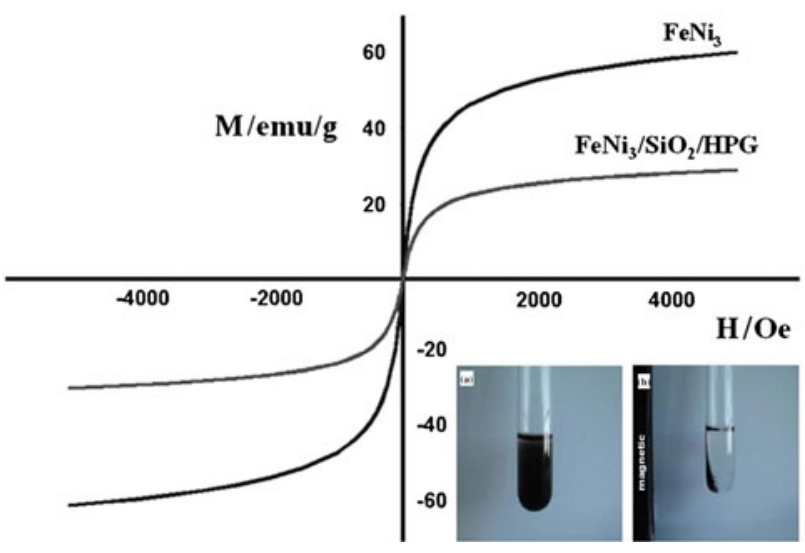

Fig. 6 Room temperature magnetization curves of the $\mathrm{FeNi}_{3} \mathrm{MNP}$ and $\mathrm{FeNi}_{3} / \mathrm{SiO}_{2} / \mathrm{HPG} \mathrm{MNP}$

Table 1 Solvent screening for the reaction between benzaldehyde, malononitrile, and dimedone

\begin{tabular}{lll}
\hline Entry & Solvent & Yield/\% $^{\mathrm{a}}$ \\
\hline 1 & $\mathrm{H}_{2} \mathrm{O}$ & 82 \\
2 & $\mathrm{EtOH}$ & 76 \\
3 & $\mathrm{CH}_{3} \mathrm{CN}$ & 57 \\
4 & $\mathrm{THF}$ & 36 \\
5 & $\mathrm{CH}_{2} \mathrm{Cl}_{2}$ & 39 \\
6 & $\mathrm{Toluene}$ & 17 \\
7 & EtOAC & 72 \\
8 & $\mathrm{MeOH}$ & 78 \\
9 & DMF & 63 \\
10 & DMSO & 67 \\
11 & Solvent free & 97 \\
12 & $n$-Hexane & Trace \\
13 & CHCl $_{3}$ & Trace \\
14 & Dioxane & Trace \\
\hline
\end{tabular}

Reaction conditions: malononitrile $(1 \mathrm{mmol})$, dimedone $(1 \mathrm{mmol})$, benzaldehyde $(1 \mathrm{mmol})$, and $0.001 \mathrm{~g} \mathrm{FeNi}_{3} / \mathrm{SiO}_{2} / \mathrm{HPG} \mathrm{MNP}$ at room temperature for $45 \mathrm{~min}$

a Isolated yields

MNP had an effective influence. The best amount of $\mathrm{FeNi}_{3} /$ $\mathrm{SiO}_{2} / \mathrm{HPG}$ MNP was $0.001 \mathrm{~g}$, which afforded the desired product in $97 \%$ yield (Fig. 7).

Progress of the reaction in the presence of $0.001 \mathrm{~g}$ $\mathrm{FeNi}_{3} / \mathrm{SiO}_{2} / \mathrm{HPG}$ MNP was monitored by gas chromatography (GC) under optimal conditions (Fig. 8). Using this catalyst system, excellent yields of $4 H$-benzo[b]pyran can be achieved in $30 \mathrm{~min}$. No apparent by-products were observed by GC in any of the experiments and the cyclic carbonate was obtained cleanly in $97 \%$ yield.

It is important to note that the magnetic property of $\mathrm{FeNi}_{3} / \mathrm{SiO}_{2} / \mathrm{HPG}$ MNP facilitates its efficient recovery from the reaction mixture during work-up procedure. The

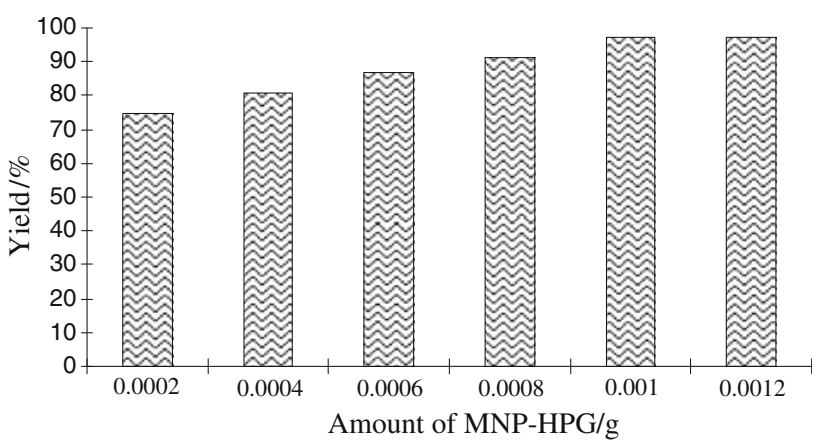

Fig. 7 Effect of increasing amount of $\mathrm{FeNi}_{3} / \mathrm{SiO}_{2} / \mathrm{HPG} \mathrm{MNP}$ on the preparation of $4 H$-benzo[b]pyran

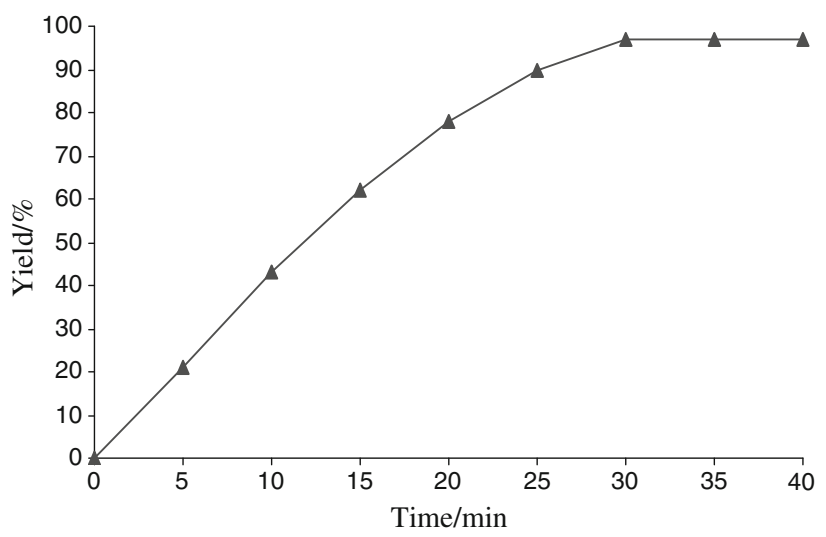

Fig. 8 Reaction progress monitored by gas chromatography (GC). Reaction conditions: dimedone $(1 \mathrm{mmol})$, benzaldehyde $(1 \mathrm{mmol})$, malononitrile $(1 \mathrm{mmol})$, and $0.001 \mathrm{~g} \mathrm{FeNi}_{3} / \mathrm{SiO}_{2} / \mathrm{HPG} \mathrm{MNP}$ at room temperature

activity of the recycled catalyst was also examined under the optimized conditions. After completion of the reaction, the catalyst was separated using an external magnet, washed with methanol and dried at the pump. The recovered catalyst was reused for eight consecutive cycles without any significant loss in catalytic activity (Fig. 9).

As can be seen from Table 2, the reaction of aromatic aldehydes with malononitrile and 1,3-diketones at room temperature under solvent-free conditions provided the corresponding $4 H$-benzo[b]pyran derivatives in good yields. The results presented in Table 2 indicate that aldehydes bearing electron-withdrawing groups react more quickly than their electron-donating aldehyde counterparts. For example, aromatic aldehydes such as 4-chloro-, 4-nitro-, and 4-bromobenzaldehydes react quickly with high product yields in comparison to 4-hydroxy-, 4-methyl-, and 4-methoxybenzaldehyde derivatives. The yield of $4 H$-benzo $[b]$ pyrans bearing group at the ortho position on the aromatic ring is lower than that of the $4 H$-benzo[b]pyrans bearing group at the para position on the aromatic ring (Scheme 1; Table 2). 


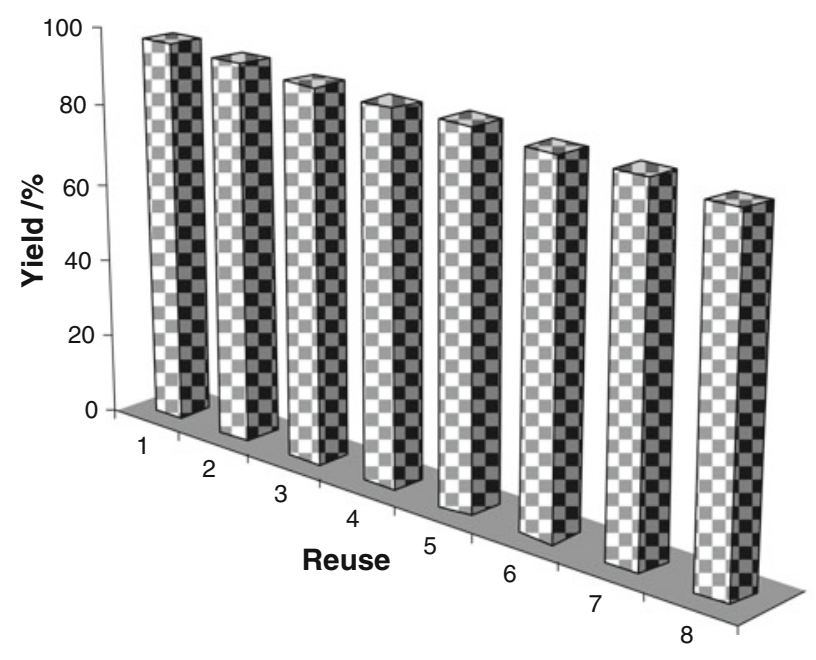

Fig. 9 Reuse performance of the catalyst
On the other hand, when benzyl cyanide was treated as a substitute for malononitrile in this reaction under similar conditions, not only was a highly prolonged time required, but the products were different. The spectroscopic data of the products confirmed that these structures belong to octahydroxanthene (Scheme 2).

In comparison with other catalysts employed for the synthesis of $4 H$-benzo[b]pyran from malononitrile, benzaldehyde, and dimedone, $\mathrm{FeNi}_{3} / \mathrm{SiO}_{2} / \mathrm{HPG} \mathrm{MNP}$ showed a much higher catalytic activity in terms of a very much shorter reaction time and mild conditions (Table 3 ).

To further explore the potential of this MNP catalyst for heterocyclic synthesis, we investigated one-pot reactions involving aromatic aldehydes, malononitrile, ethyl acetoacetate, and hydrazine hydrate and obtained pyranopyrazoles in excellent yields (Scheme 3; Table 4). This methodology was evaluated using a variety of different

Table 2 Synthesis of $4 H$-benzo[b]pyran derivatives catalyzed by $\mathrm{FeNi}_{3} / \mathrm{SiO}_{2} / \mathrm{HPG} \mathrm{MNP}$

\begin{tabular}{|c|c|c|c|c|c|c|c|}
\hline Entry & $\mathrm{R}$ & 1,3-Diketone & Product & Time/min & Yield $/ \%^{\mathrm{a}, \mathrm{b}}$ & M.p. (obs) $/{ }^{\circ} \mathrm{C}$ & M.p. (lit) $/{ }^{\circ} \mathrm{C}$ \\
\hline 1 & $\mathrm{C}_{6} \mathrm{H}_{5}$ & 1a & $4 a$ & 30 & 97 & $228-230$ & $224[25]$ \\
\hline 2 & $4-\mathrm{ClC}_{6} \mathrm{H}_{4}$ & $1 \mathrm{a}$ & $4 b$ & 30 & 96 & 207-209 & $209-211$ [25] \\
\hline 3 & $2-\mathrm{ClC}_{6} \mathrm{H}_{4}$ & 1a & $4 c$ & 35 & 94 & $210-212$ & $214-215$ [25] \\
\hline 4 & $4-\mathrm{MeC}_{6} \mathrm{H}_{4}$ & 1a & $4 d$ & 40 & 90 & $228-230$ & $223-225[25]$ \\
\hline 5 & $4-\mathrm{NO}_{2} \mathrm{C}_{6} \mathrm{H}_{4}$ & 1a & $4 e$ & 30 & 94 & $183-186$ & $179-180[25]$ \\
\hline 6 & $2-\mathrm{NO}_{2} \mathrm{C}_{6} \mathrm{H}_{4}$ & 1a & $4 f$ & 35 & 92 & $217-220$ & $222-223[26]$ \\
\hline 7 & $4-\mathrm{BrC}_{6} \mathrm{H}_{4}$ & 1a & $4 \mathrm{~g}$ & 30 & 95 & $200-202$ & $203-205$ [26] \\
\hline 8 & 2- $\mathrm{BrC}_{6} \mathrm{H}_{4}$ & $1 \mathrm{a}$ & $4 h$ & 35 & 93 & $152-154$ & $150-152[26]$ \\
\hline 9 & 4- $\mathrm{MeOC}_{6} \mathrm{H}_{4}$ & 1a & $4 i$ & 40 & 91 & 201-202 & $199-201[25]$ \\
\hline 10 & $4-\mathrm{HOC}_{6} \mathrm{H}_{4}$ & 1a & $4 \mathbf{j}$ & 40 & 89 & 201-204 & 206-208 [25] \\
\hline 11 & $4-\mathrm{FC}_{6} \mathrm{H}_{4}$ & 1a & $4 k$ & 35 & 97 & $188-190$ & 192-194 [27] \\
\hline 12 & 4- $\left(\mathrm{Me}_{2} \mathrm{~N}\right) \mathrm{C}_{6} \mathrm{H}_{4}$ & 1a & 41 & 40 & 88 & 199-201 & $198-200[25]$ \\
\hline 13 & $\mathrm{C}_{6} \mathrm{H}_{5}$ & 1b & $4 m$ & 30 & 95 & $235-237$ & $239-241$ [28] \\
\hline 14 & $4-\mathrm{ClC}_{6} \mathrm{H}_{4}$ & $1 \mathrm{~b}$ & $4 n$ & 30 & 97 & $222-224$ & $226-229[28]$ \\
\hline 15 & $2-\mathrm{ClC}_{6} \mathrm{H}_{4}$ & $1 \mathbf{b}$ & 40 & 30 & 95 & $213-215$ & $210-212[28]$ \\
\hline 16 & $4-\mathrm{MeC}_{6} \mathrm{H}_{4}$ & $1 \mathbf{b}$ & $4 p$ & 40 & 93 & $224-226$ & $223-225[28]$ \\
\hline 17 & $4-\mathrm{NO}_{2} \mathrm{C}_{6} \mathrm{H}_{4}$ & $1 b$ & $4 q$ & 35 & 95 & $235-236$ & $234-236[28]$ \\
\hline 18 & $2-\mathrm{NO}_{2} \mathrm{C}_{6} \mathrm{H}_{4}$ & $1 b$ & $4 r$ & 35 & 92 & $191-193$ & 196-198 [28] \\
\hline 19 & $4-\mathrm{MeOC}_{6} \mathrm{H}_{4}$ & $1 \mathbf{b}$ & $4 s$ & 40 & 89 & $188-190$ & $193-195[28]$ \\
\hline 20 & $4-\mathrm{HOC}_{6} \mathrm{H}_{4}$ & $1 \mathbf{b}$ & $4 t$ & 40 & 88 & 229-232 & $234-236[28]$ \\
\hline 21 & $4-\mathrm{FC}_{6} \mathrm{H}_{4}$ & $1 \mathbf{b}$ & $4 u$ & 30 & 96 & $217-220$ & $213-215$ [28] \\
\hline 22 & $4-\left(\mathrm{Me}_{2} \mathrm{~N}\right) \mathrm{C}_{6} \mathrm{H}_{4}$ & 1b & $4 v$ & 40 & 89 & $173-175$ & $168-170[28]$ \\
\hline 23 & $\mathrm{C}_{6} \mathrm{H}_{5}$ & 1c & $4 w$ & 35 & 96 & $193-195$ & 194-196 [27] \\
\hline 24 & $4-\mathrm{ClC}_{6} \mathrm{H}_{4}$ & 1c & $4 x$ & 30 & 97 & $173-175$ & $175-177[27]$ \\
\hline 25 & 4- $\mathrm{MeC}_{6} \mathrm{H}_{4}$ & 1c & $4 y$ & 40 & 92 & $180-182$ & $177-179[27]$ \\
\hline 26 & $4-\mathrm{MeOC}_{6} \mathrm{H}_{4}$ & 1c & $4 z$ & 40 & 91 & $140-142$ & $137-139[27]$ \\
\hline 27 & $4-\mathrm{NO}_{2} \mathrm{C}_{6} \mathrm{H}_{4}$ & $1 \mathrm{c}$ & $4 \mathbf{a}^{\prime}$ & 30 & 98 & $183-185$ & $180-183[27]$ \\
\hline
\end{tabular}

${ }^{a}$ Reaction condition: benzaldehyde derivatives $(1 \mathrm{mmol}), 1,3$-diketones ( $\left.1 \mathrm{mmol}\right)$, malononitrile $(1 \mathrm{mmol}), 0.001 \mathrm{~g} \mathrm{FeNi} / \mathrm{SiO}_{2} / \mathrm{HPG} \mathrm{MNP}$ at room temperature under solvent-free conditions

b Yield refers to isolated product 
substituted aromatic aldehydes in the presence of magnetic nanocatalyst under similar conditions. Aromatic aldehydes, carrying either electron-withdrawing or electron-donating substituents, afforded high yields of products with high purity; the results are presented in Table 4 . The four-component cyclocondensation reaction proceeded smoothly and was completed in $35-50$ min.

\section{Conclusion}

In conclusion, we have developed current important areas in the heterogenization of $\mathrm{HPG}$ - a rapidly developing research area. The main objectives are to develop roomtemperature, solvent-free conditions, a rapid (immediate) and easy immobilization technique, and low-cost precursors for the preparation of highly active and stable MPs with high densities of functional groups. Furthermore, applying the exciting new area of magnetic particles that are intrinsically not magnetic, but can be magnetized readily by an external magnet, can have a positive effect on high activity on the one hand and separation and recycling on the other.

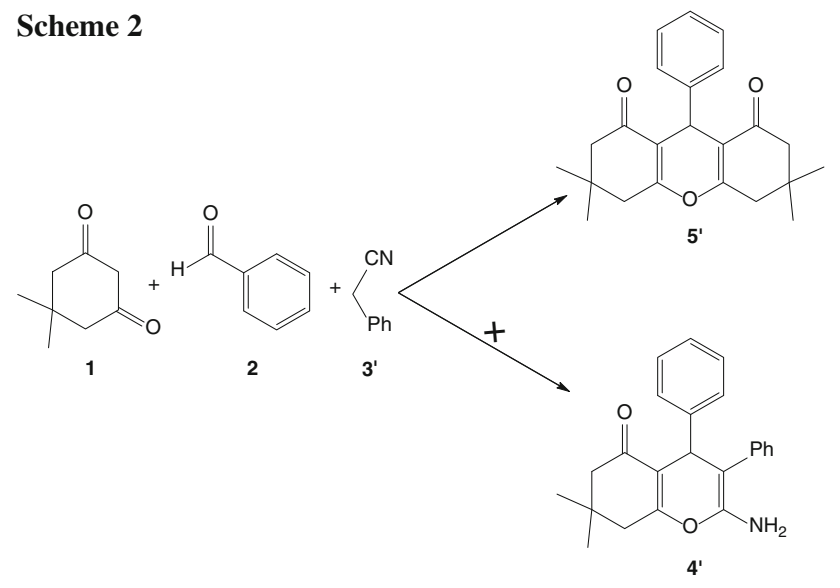

\section{Experimental}

Chemical materials were purchased from Fluka (Buchs, Switzerland) and Merck (Darmstadt, Germany) in high purity. Melting points were determined in open capillaries using an Electrothermal 9100 apparatus (http://www. electrothermal.com). Morphology was analyzed using highresolution transmission electron microscopy (HRTEM) on a JEOL transmission electron microscope (http://www.jeol. com) operating at $200 \mathrm{kV}$. Powder X-ray diffraction data was obtained using Bruker D8 Advance model with $\mathrm{Cu}-\mathrm{K} \alpha$ radiation. The thermogravimetric analysis (TGA) was carried out on a NETZSCH STA449F3 (http://www.netzschthermal-analysis.com) at a heating rate of $10{ }^{\circ} \mathrm{C} \mathrm{min}-1$ under nitrogen. The magnetic measurement was carried out in a vibrating sample magnetometer (VSM) (4 inch, Daghigh Meghnatis Kashan, Kashan, Iran) at room temperature. NMR spectra were recorded in DMSO- $d_{6}$ on a Bruker Avance DRX-400 MHz instrument spectrometer (http:// www.bruker.com/) using tetramethylsilane (TMS) as internal standard. IR spectra were recorded on a Perkin Elmer 781 (http://www.perkinelmer.com/). Mass spectra were recorded on Shimadzu GCMS-QP5050 mass spectrometer (Shimadzu, Tokyo, Japan). The purity determination of the products and reaction monitoring were accomplished by thin layer chromatography (TLC) on silica gel polygram SILG/UV 254 plates.

\section{Synthesis of $\mathrm{FeNi}_{3} \mathrm{MNPS}$}

$\mathrm{FeCl}_{2} \cdot 4 \mathrm{H}_{2} \mathrm{O}(1.72 \mathrm{~g})$ and $4.72 \mathrm{~g} \mathrm{NiCl} 2 \cdot 6 \mathrm{H}_{2} \mathrm{O}$ were dissolved in $80 \mathrm{~cm}^{3}$ deaerated highly purified water contained in a three-neck flask with vigorous stirring $(800 \mathrm{rpm})$ under nitrogen. As the temperature was elevated to $80{ }^{\circ} \mathrm{C}$, $10 \mathrm{~cm}^{3}$ ammonium hydroxide was added drop by drop, and the reaction was maintained for $30 \mathrm{~min}$. The black product was separated by placing the vessel on a permanent magnet and the supernatant was decanted. The black precipitate
Table 3 Comparison of the catalytic efficiency of $\mathrm{FeNi}_{3} /$ $\mathrm{SiO}_{2} / \mathrm{HPG}$ MNP with that of other catalysts

a Isolated yield, conditions: malononitrile (1 mmol), benzaldehyde $(1 \mathrm{mmol})$, and dimedone $(1 \mathrm{mmol})$

\begin{tabular}{lllllll}
\hline Entry & Catalyst & Condition & Solvent & Amount catalyst/g & Time/min & Yield/\% \\
\hline 1 & $\mathrm{Yb}(\mathrm{PFO})_{3}$ & $60{ }^{\circ} \mathrm{C}$ & $\mathrm{EtOH}$ & 1.8 & 300 & $90[17]$ \\
2 & $\begin{array}{l}\text { Tetramethylammonium } \\
\text { hydroxide }\end{array}$ & r.t. & $\mathrm{H}_{2} \mathrm{O}$ & 0.09 & $30-120$ & $81[18]$ \\
3 & $\mathrm{Na}_{2} \mathrm{SeO}_{4}$ & Reflux & $\mathrm{H}_{2} \mathrm{O} / \mathrm{EtOH}$ & 0.1 & & \\
4 & $\mathrm{LiBr}$ & Reflux & $\mathrm{H}_{2} \mathrm{O}$ & 8.7 & 60 & $97[19]$ \\
5 & $\mathrm{NaBr}$ & $20{ }^{\circ} \mathrm{C}$ & $n-\mathrm{PrOH}$ & 0.01 & 15 & $95[20]$ \\
6 & $\mathrm{MgO}$ & r.t. & $\mathrm{H}_{2} \mathrm{O}$ & 0.02 & 25 & $84[21]$ \\
7 & $\mathrm{NaBr}$ & $\mathrm{MW}$ & - & 0.042 & 30 & $75[22]$ \\
8 & $\mathrm{SB}-\mathrm{DABCO}$ & r.t. & EtOH & 0.06 & 10 & $95[23]$ \\
9 & $\mathrm{FeNi}_{3} / \mathrm{SiO}_{2} / \mathrm{HPG} \mathrm{MNP}$ & r.t. & $\mathrm{None}$ & 0.001 & 35 & $96[24]$ \\
\hline
\end{tabular}


Scheme 3

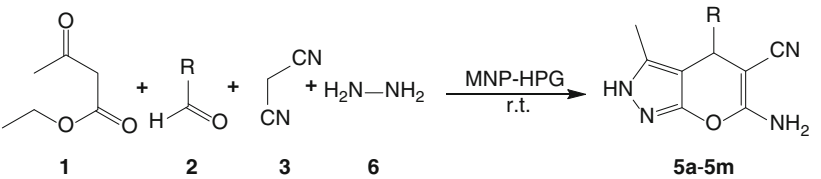

Table 4 Synthesis of pyranopyrazoles from various aromatic aldehydes, malononitrile, ethyl acetoacetate, and hydrazine hydrate in the presence of magnetic nanocatalyst at room temperature under solventfree conditions

\begin{tabular}{llllll}
\hline Product $^{\mathrm{a}}$ & $\mathrm{R}$ & $\begin{array}{l}\text { Yield/ } \\
\%^{\mathrm{b}}\end{array}$ & $\begin{array}{l}\text { Time/ } \\
\text { min }\end{array}$ & $\begin{array}{l}\text { M.p. } \\
\text { (obs)/ } /{ }^{\circ} \mathrm{C}\end{array}$ & $\begin{array}{l}\text { M.p. } \\
\text { (lit)/ } /{ }^{\circ} \mathrm{C}\end{array}$ \\
\hline $\mathbf{5 a}$ & $\mathrm{C}_{6} \mathrm{H}_{5}$ & 94 & 35 & 244 & $245-246[29]$ \\
$\mathbf{5 b}$ & $4-\mathrm{ClC}_{6} \mathrm{H}_{4}$ & 95 & 35 & 233 & $234-235[30]$ \\
$\mathbf{5 c}$ & $2-\mathrm{ClC}_{6} \mathrm{H}_{4}$ & 91 & 45 & 245 & $245-246[31]$ \\
$\mathbf{5 d}$ & $4-\mathrm{MeC}_{6} \mathrm{H}_{4}$ & 93 & 50 & 197 & $197-198[32]$ \\
$\mathbf{5 e}$ & $4-\mathrm{NO}_{2} \mathrm{C}_{6} \mathrm{H}_{4}$ & 92 & 35 & 250 & $251-252[29]$ \\
$\mathbf{5 f}$ & $2-\mathrm{NO}_{2} \mathrm{C}_{6} \mathrm{H}_{4}$ & 90 & 40 & 240 & $242-243[32]$ \\
$\mathbf{5 g}$ & $4-\mathrm{BrC}_{6} \mathrm{H}_{4}$ & 92 & 45 & 249 & $249-250[32]$ \\
$\mathbf{5 h}$ & $3-\mathrm{BrC}_{6} \mathrm{H}_{4}$ & 88 & 50 & 233 & $223-224[29]$ \\
$\mathbf{5 i}$ & $2-\mathrm{MeOC}_{6} \mathrm{H}_{4}$ & 91 & 50 & 250 & $252-253[32]$ \\
$\mathbf{5 j}$ & $4-\mathrm{MeOC}_{6} \mathrm{H}_{4}$ & 92 & 45 & 212 & $212-213[33]$ \\
$\mathbf{5 k}$ & $4-\mathrm{HOC}_{6} \mathrm{H}_{4}$ & 88 & 45 & 224 & $223-224[33]$ \\
$\mathbf{5 l}$ & $4-\mathrm{FC}_{6} \mathrm{H}_{4}$ & 90 & 40 & 246 & $247-248[32]$ \\
$\mathbf{5 m}$ & $4-\left(\mathrm{Me}_{2} \mathrm{~N}_{2} \mathrm{C}_{6} \mathrm{H}_{4}\right.$ & 92 & 50 & 220 & $219-220[32]$ \\
\hline
\end{tabular}

${ }^{a}$ All products were identified and characterized by comparison with authentic samples

b Yield refers to isolated product

was washed six times with highly purified water to remove unreacted chemicals, then the black product $\mathrm{FeNi}_{3}$ was dried under vacuum.

\section{Synthesis of $\mathrm{FeNi}_{3} / \mathrm{SiO}_{2} \mathrm{MNPS}$}

First, a mixture of $100 \mathrm{~cm}^{3}$ ethanol and $20 \mathrm{~cm}^{3}$ distilled water was added to $1 \mathrm{~g}$ magnetite nanoparticles, and the resulting dispersion was sonicated for $10 \mathrm{~min}$. After adding $2.5 \mathrm{~cm}^{3}$ ammonia water, $2 \mathrm{~cm}^{3}$ tetraethyl orthosilicate (TEOS) was added to the reaction solution. The resulting dispersion was mechanically stirred continuously for $20 \mathrm{~h}$ at room temperature. The magnetic $\mathrm{FeNi}_{3} / \mathrm{SiO}_{2}$ nanoparticles were collected by magnetic separation and washed with ethanol and deionized water in sequence.

\section{Synthesis of $\mathrm{FeNi}_{3} / \mathrm{SiO}_{2} / \mathrm{HPG} \mathrm{MNPs}$}

For synthesis of $\mathrm{FeNi}_{3} / \mathrm{SiO}_{2} / \mathrm{HPG}$ MNPs, 2 mmol $\mathrm{FeNi}_{3} /$ $\mathrm{SiO}_{2}$ MNPs were dispersed in a mixture of $80 \mathrm{~cm}^{3}$ toluene and $1.0 \mathrm{mmol}$ potassium methanolate $\left(\mathrm{CH}_{3} \mathrm{OK}\right)$, followed by the addition of $10 \mathrm{~cm}^{3}$ anhydrous dioxane. Glycidol $(2.0 \mathrm{~g})$ was added dropwise over a period of $15 \mathrm{~h}$. After vigorous stirring for $2 \mathrm{~h}$, the final suspension was repeatedly washed, filtered several times, and air-dried at $60{ }^{\circ} \mathrm{C}$.

General procedure for the synthesis of $4 \mathrm{H}$ benzo[b]pyran

A mixture of aromatic aldehyde $(1 \mathrm{mmol})$, dimedone (1 mmol), malononitrile $(1 \mathrm{mmol})$, and $0.001 \mathrm{~g} \mathrm{FeNi}_{3} /$ $\mathrm{SiO}_{2} / \mathrm{HPG}$ MNP was stirred at room temperature under solvent-free conditions for the appropriate time (Table 2). Upon completion (the progress of the reaction was monitored by TLC), EtOH was added to the reaction mixture and the $\mathrm{FeNi}_{3} / \mathrm{SiO}_{2} / \mathrm{HPG}$ MNP was separated by external magnet. The solvent was then removed from solution under reduced pressure and the resulting product purified by recrystallization using ethanol.

\section{General procedure for the synthesis of pyranopyrazoles}

A mixture of ethyl acetoacetate $(1 \mathrm{mmol})$, hydrazine hydrate $(1 \mathrm{mmol})$, malononitrile $(1 \mathrm{mmol})$, aldehyde ( $1 \mathrm{mmol}$ ), and $0.001 \mathrm{~g} \mathrm{FeNi}_{3} / \mathrm{SiO}_{2} / \mathrm{HPG}$ MNPs was stirred at room temperature under solvent-free conditions for the appropriate time (Table 4). Upon completion (the progress of the reaction was monitored by TLC), EtOH was added to the reaction mixture and the $\mathrm{FeNi}_{3} / \mathrm{SiO}_{2} / \mathrm{HPG}$ MNPs was separated by external magnet. The solvent was then removed from solution under reduced pressure and the resulting product purified by recrystallization using ethanol.

Open Access This article is distributed under the terms of the Creative Commons Attribution License which permits any use, distribution, and reproduction in any medium, provided the original author(s) and the source are credited.

\section{References}

1. Zhu CL, Zhang ML, Qiao YJ, Xiao G, Zhang F, Chen YJ (2010) J Phys Chem C 114:16229

2. Hu JQ, Bando Y, Zhan JH, Golberg D (2004) Appl Phys Lett $85: 3593$

3. Liu B, Zeng HC (2005) Small 1:566

4. Cao J, Sun JZ, Hong J, Li HY, Chen HZ, Wang M (2004) Adv Mater 16:84

5. Sun XM, Li YD (2004) Angew Chem Int Ed 43:597

6. Wang QB, Liu Y, Ke YG, Yan H (2008) Angew Chem Int Ed 47:316

7. Lyon JL, Fleming DA, Stone MB, Schiffer P, Williams ME (2004) Nano Lett 4:719

8. Yang PP, Quan ZW, Hou ZY, Li CX, Kang XJ, Cheng ZY, Lin J (2009) Biomaterials 30:4786

9. Zhang M, Wu YP, Feng XZ, He XW, Chen LX, Zhang YK (2010) J Mater Chem 20:5835 
10. Liu SS, Chen HM, Lu XH, Deng CH, Zhang XM, Yang PY (2010) Angew Chem Int Ed 49:7557

11. Won YH, Aboagye D, Jang HS, Jitianu A, Stanciu LA (2010) J Mater Chem 20:5030

12. Li Y, Wu JS, Qi DW, Xu XQ, Deng CH, Yang PY, Zhuang XM (2008) Chem Commun 2008:564

13. Foye WO (1991) Principal di Chemico Farmaceutica. Piccin, Padova, p 416

14. Singh K, Singh J, Singh H (1996) Tetrahedron 52:14273

15. Wang XS, Shi DQ, Tu ST, Yao CS (2003) Synth Commun 33:119

16. Armesto D, Horspool WM, Martin N, Ramos A, Seaone C (1989) J Org Chem 54:3069

17. Wang LM, Shao JH, Tian H, Wang YH, Liu B (2006) J Fluorine Chem 127:97

18. Balalaie S, Sheikh-Ahmadi M, Bararjanian M (2007) Catal Commun 8:1724

19. Hekmatshoar R, Majedi S, Bakhtiari K (2008) Catal Commun 9:307

20. Sun WB, Zhang P, Fan J, Chen SH, Zhang ZH (2010) Synth Commun 40:587

21. Elinson MN, Dorofeev AS, Feducovich SK, Gorbunov SV, Nasybullin RF, Miloserdov FM, Nikishin GI (2006) Eur J Org Chem 2006:4335
22. Kumar D, Reddy VB, Sharad S, Dube U, Kapur S (2009) Eur J Med Chem 44:3805

23. Devi I, Bhuyan PJ (2004) Tetrahedron Lett 45:8625

24. Hasaninejada A, Shekouhya M, Golzara N, Zareb A, Doroodmand MM (2011) Appl Catal A 402:11

25. Fotouhi L, Heravi MM, Fatehi A, Bakhtiari K (2007) Tetrahedron Lett 48:5379

26. Hekmatshoar R, Majedi S, Bakhtiari K (2008) Catal Commun 9:307

27. Kumar D, Reddy VB, Sharad S, Dube U, Kapur S (2009) Eur J Med Chem 44:3805

28. Rathod S, Arbad B, Lande M (2010) Chin J Catal 31:631

29. Sharanin YA, Sharanina LG, Puzanova VV (1983) J Org Chem USSR (Engl Transl) 1983:2291

30. Harb AA, Hesien AM, Metwally SA, Elnagdi MH (1989) Liebigs Ann Chem 1989:585

31. Abdel-Latif FF (1990) Z Naturforsch B: Chem Sci 45:1675

32. Sharanina LG, Promonenkov LG, Puzanova VV, Sharanona YA (1982) Chem Heterocycl Comp 18:607

33. Peng Y, Song G, Dou R (2006) Green Chem 8:573 